\title{
An Unusual Case of Congenitally Unguarded Tricuspid Valve Orifice Associated with Pulmonary Valve Atresia and Intact Ventricular Septum
}

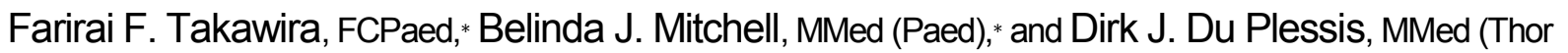 \\ Surg) $t$ \\ Departments of *Paediatric Cardiology and †Cardiothoracic Surgery, Steve Biko Academic Hospital and \\ University of Pretoria, Pretoria, South Africa
}

We report on a premature neonate who presented with cyanosis soon after birth. She was found on echocardiography to have an unguarded tricuspid valve orifice associated with pulmonary valve atresia and an intact interventricular septum. Owing to the small-sized pulmonary arteries, she was initially managed conservatively with prostaglandin infusion, and at one year of age underwent a successful bidirectional cavo-pulmonary (Glenn) shunt operation. (Echocardiography 2010;27:202-204)

Key words: unguarded, tricuspid valve, pulmonary valve atresia, Ebstein's, cavo-pulmonary, Fontan

The unguarded tricuspid valve (TV) orifice is a rare congenital heart malformation. It consists of partial or complete agenesis of the TV tissue and its apparatus, and is often associated with pulmonary valve atresia. It has, however, been reported with a patent pulmonary valve (PV). There are little data available on the management of these patients. The literature is limited to case reports that are based mostly on postmortem findings. Herein, we describe the clinical and echocardiographic findings in an infant medically managed until a bidirectional Glenn shunt could be performed.

\section{Case Report:}

The infant is a $1.9 \mathrm{~kg}, 36$ wk gestation female born to a 27 -year-old HIV-positive female. The baby was cyanosed at birth and did not respond to oxygen or intubation with mechanical ventilation. On physical examination, the baby was not dysmorphic and the oxygen saturation was $75 \%$. The apex beat was not displaced. A 2/6 ejection systolic murmur was audible in the second left intercostal space. Chest radiography demonstrated mild cardiomegaly with oligemic lung fields. Electrocardiography revealed an HR of $150 /$ min, sinus rhythm, and a QRS axis of +75 degrees. The P-waves were tall and peaked, indicating right atrial enlargement. There were poor right ventricular forces with dominance of the left ventricle.

Transthoracic echocardiography (Fig. 1A) demonstrated a large unguarded TV orifice in the normal position. There were no TV leaflets, chordae tendinae, or papillary muscles present. The right atrium (RA) was dilated with the interatrial septum deviating to the left. A small atrial septal defect (ASD) with right-toleft shunting was evident. Color flow Doppler echocardiography demonstrated swirling of blood in the RA, right ventricle (RV), and across the unguarded TV orifice (Fig. 1B). Spectral Doppler interrogation across the unguarded TV orifice demonstrated low velocity systolic-diastolic flow. There was also PV atresia with no prograde flow from the RV across the PV. The pulmonary arteries (PAs) were small and measured only 2 $\mathrm{mm}$. They were fed retrogradely from a patent ductus arteriosus (PDA). Treatment with prostaglandin VR infusion was commenced soon after birth to maintain ductal patency. Her saturations improved from $75 \%$ to $90 \%$. The PAs were deemed too small to accommodate a systemic-to-pulmonary-artery shunt. She was therefore maintained on the prostaglandin infusion for two weeks. After it was discontinued, the PDA

Prior publication: Nil Support/Grants: Nil Conflicts of interest: Nil Permissions: Nil

Prior presentations: Presented at the 7th Annual Congress of the South African Heart Association, Somerset West, Cape Town, South Africa, $30^{\text {th }}$ October-1st November 2006

Address for correspondence and reprint requests: Dr. Farirai F. Takawira, Department of Paediatric Cardiology, Level D3—Department of Paediatrics, Steve Biko Academic Hospital and University of Pretoria, P Bag X 169, Pretoria, 0001, South Africa. Fax: +27123545275; E-mail: fari.takawira@up.ac.za 


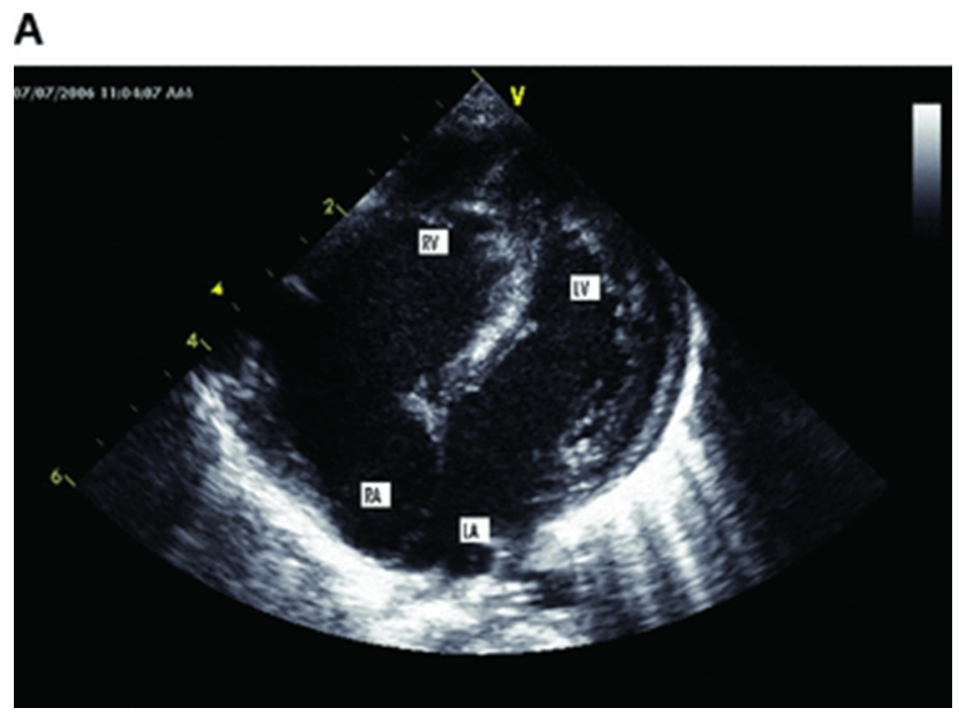

\section{B}

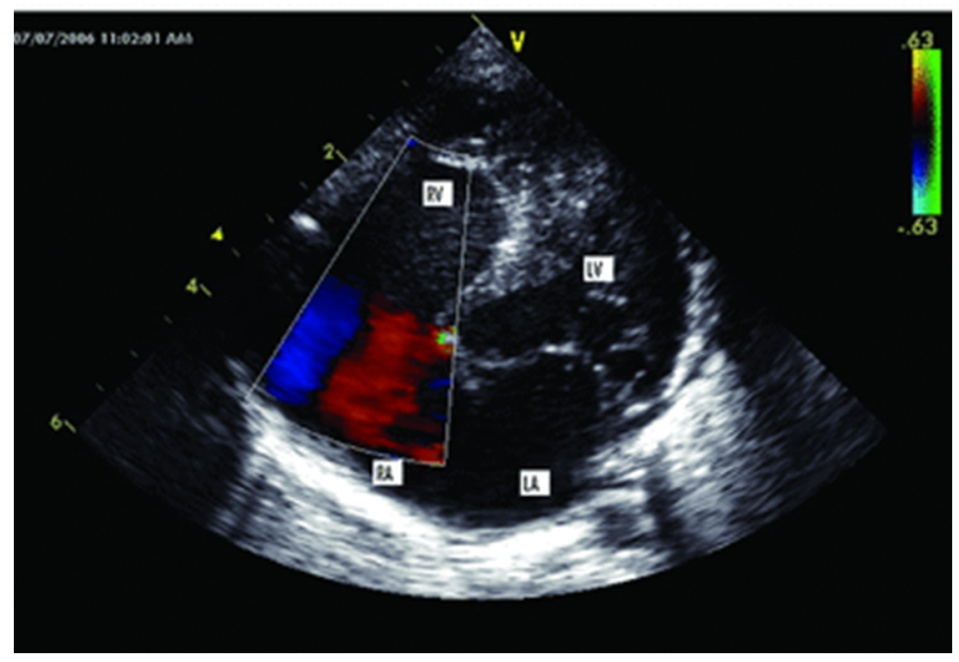

Figure 1. Transthoracic echocardiography. Apical four-chamber view in diastole A. demonstrating absent $T V$ leaflets, chordae, and papillary muscles, and in systole B. with color flow Doppler. (RA = right atrium; $L A=$ left atrium; $R V=$ right ventricle; $L V=$ left ventricle.

remained patent, and she could maintain saturations above $75 \%$. After in-hospital monitoring for eight weeks the baby was discharged to home followed by frequent out patient visits. At seven months of age the baby's saturations decreased to $60 \%$. Echo Doppler showed a smaller PDA and pulmonary arteries that were large enough for surgical intervention. Surgery, however, was delayed until one year of age due to maternal ill health. At that time, the child had a successful bidirectional Glenn shunt. Preoperative transesophageal echocardiography (Fig. 2) confirmed the transthoracic echocardiographic findings. She is currently maintaining saturations of $83 \%$ and thriving. An extracardiac conduit Fontan operation is envisaged when she reaches four or five years old. 


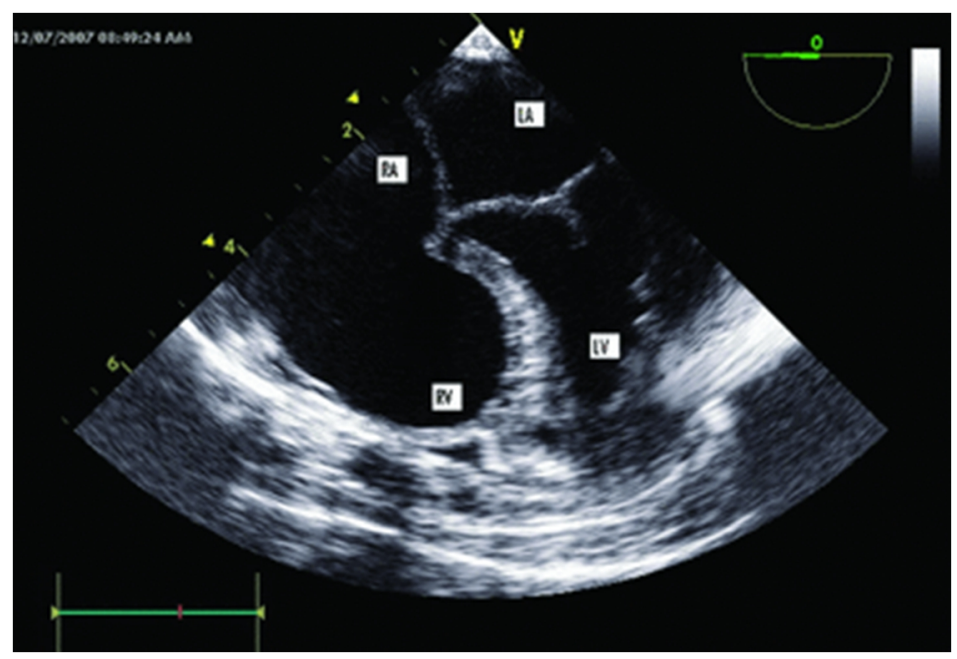

Figure 2. Transesophageal echocardiography. Four-chamber view in systole confirming absent TV tissue and apparatus ( $R A=$ right atrium; $L A=$ left atrium; $R V=$ right ventricle; $L V=$ left ventricle).

\section{Discussion:}

Ebstein's anomaly, a defect in which the TV leaflets are fused and displaced inferiorly into the right ventricular cavity was first described in $1866 .{ }^{1}$ The unguarded TV orifice is a rare congenital malformation of the heart, characterized by the absence of TV tissue ${ }^{2-4}$ with an existing orifice. It represents the extreme form of Ebstein's anomaly. There is partial or complete agenesis of the TV tissue including chordae and papillary muscles. It is typically associated with pulmonary valve atresia and an intact ventricular septum, though it has been described with a patent right ventricular outflow tract. ${ }^{3,5-9}$ The initial case of absent TV tissue was a necropsy report in $1938^{2}$ and the term "unguarded tricuspid orifice" was coined in 1964 by Kanjuh. ${ }^{3}$ In 1990, Anderson reported 46 cases of pulmonary atresia and intact ventricular septum which included three cases of unguarded TV. ${ }^{4}$ There are less than 20 antemortem reported cases in the English literature. ${ }^{8}$ The condition usually presents clinically in early infancy with cyanosis, due to decreased pulmonary blood flow, when associated with pulmonary atresia. This was the case in our patient. When there is patency of the right ventricular outflow tract, these patients may present later in life with signs of right heart failure, arrhythmias or thrombus formation due to the giant $\mathrm{RA}^{8,9}$ In most institutions, the management of patients with an unguarded TV orifice when associated with pulmonary atresia involves initial palliation with a systemic-to-pulmonary-artery shunt or stenting of the PDA to increase pulmonary blood flow. ${ }^{10,11}$

In our case, prematurity and small pulmonary arteries prevented palliation in the newborn period. Thus, initially prostaglandins were used to maintain ductal patency and insure adequate saturation. Fortunately, after prostaglandins were discontinued ductal patency continued until the initial palliation with a bidirectional Glenn shunt could be achieved. Echocardiographic imaging combined with color Doppler was important in the initial diagnosis and the out patient management. The establishment of a total cavopulmonary connection (TCPC) at a later stage is the long-term desired outcome. To our knowledge, there have only been two other reported surgical successes in this condition. Both patients had an initial palliation with a systemic-to-pulmonary-artery shunt followed by a bidirectional Glenn shunt. ${ }^{10,11} \mathrm{~A}$ twoventricle repair approach is often not possible due to the free tricuspid regurgitation and RV dtysfunction. ${ }^{11,12}$ 


\section{References}

1. Ebstein W: Ueber einen sehr seltenen Fall von Insufficienz der Valvula tricuspidalis, bedingt durch eine angeborene hochgradige Missbildung derselben. Arch Anat Physiol 1866;33:238-254.

2. Klein $\mathrm{H}$ : Uber einen seltenen Fall von herzmissbildung mit rudimentarer entwicklung des rechten ventrikels and defekt der tricuspidal klappen. Virchows Arch 1938;310:1-36. 3

3. Kanjuh VI, Stevenson JE, Amplatz K, et al: Congenitally Unguarded tricuspid orifice with coexistent pulmonary atresia. Circulation 1964;30:911-917.

4. Anderson $\mathrm{RH}$, Silverman NH, Zuberbuhler JR: Congenitally unguarded tricuspid orifice: Its differentiation from Ebstein's malformation in association with pulmonary atresia and intact ventricular septum. Pediatr Cardiol 1990;11:86-91.

5. Mohan JC, Tatke M, Arora R: Rudimemntary dysplastic valvular tissue guarding the tricuspid orifice with dilatation of the right ventricle and a patent outflow tract. Int $\mathrm{J}$ cardiol 1989;25:136-139.

6. Ozkutlu S, Gunal N, Caglar M, et al: Unguarded tricuspid orifice: A rare malformation of tricuspid valve diagnosed by echocardiography. Report of 2 cases and review of the literature. Int J Cardiol 1996;56:125-129.

7. Mohan JC, Passey R, Arora R: Echocardiographic spectrum of congenitally unguarded tricuspid valve orifice and patent right ventricular outflow tract. Int J Cardiol 2000;74:15357.

8. Mohan JC, Passey R, Arora R: Unguarded tricuspid orifice and patent right ventricular outflow tract presenting with long standing severe right heart failure in an adult. Int $\mathrm{J}$ Cardiol 1998;66:85-87.

9. Mohan JC, Sengupta PP, Arora R: Congenitally unguarded tricuspid valve orifice with a giant right atrium and a massive clot in an asymptomatic adult. Indian Heart $\mathrm{J}$ 2001;53:503-504.

10. Magee AG, Rosenthal E, Bostock J, et al: Unguarded tricuspid orifice with pulmonary atresia: Successful radiofrequency ablation of an accessory pathway in an infant. Heart 1998;79:101-103.

11. Hirota M, Kawada M, Ishino K, et al: Staged Fontan's operation for unguarded tricuspid orifice with pulmonary atresia. Eur J Cardiothorac Surg 2008;34:111-112.

12. Magotra RA, Agrawal NB, Mall SP, et al: Severe dysplasia of the tricuspid valve (unguarded tricuspid annulus): Clinical presentation and surgical treatment. J Thorac Cardiovasc Surg 1990;99:174-175. 